Original Article

\title{
Analysis of direct metal laser sintering - DMLS and heat treatment influence on the Inconel 713C nickel alloy structure
}

\author{
Jakub Ciftci 1, * Ryszard Sitek 1(1) and Jarosław Mizera 1이 \\ 1 Faculty of Materials Science and Engineering, Warsaw University of Technology, 141 Woloska St, 02-507 \\ Warsaw, Poland; jakub.ciftci.stud@pw.edu.pl (J.C.); ryszard.sitek@pw.edu.pl (R.S); \\ jarosław.mizera@pw.edu.pl (J.M.) *Correspondence: jakub.ciftci.stud@pw.edu.pl (J.C.) \\ Received: 07.05.2021; Accepted: 01.06.2021
}

\begin{abstract}
The group of nickel-based superalloys produced in the DMLS (Direct Metal Laser Sintering) process is limited to materials, which produced conventionally do not have properties to allow to use them for rotating components of aircraft engines. This work attempts to optimize the technological parameters of the DMLS process for the Inconel 713C nickel superalloy. A heat treatment was performed for selected samples to investigate the effect on the morphology of the $\mathrm{Ni} 3 \mathrm{Al}$ phase. The microstructure analysis and hardness tests were carried out. The material after the DMLS process was characterized by the presence of much smaller dendrites than the cast material and exceeded its hardness. Additionally, for the tested variants of heat treatment, the material was characterized by smaller sizes of the $\mathrm{Ni} 3 \mathrm{Al}$ phase by more than half. In order to ensure the stability of the microstructure, further optimization of the dedicated heat treatment after the DMLS process is required, as the standard heat treatment for Inconel 713C cast nickel superalloy does not fully recrystallize the material.
\end{abstract}

Keywords: Inconel 713C; DMLS; EOS M100

\section{Introduction}

The development of aircraft engines in the coming years will focus on reducing the emission of harmful NOx compounds to the atmosphere due to the adopted legal acts [1]. One of the methods of limitation may be increasing the operating temperature of the turbine, which will lead to increased combustion efficiency of fuel mixtures in the combustion chamber [2]. Operating temperature extremes, which may exceed $1200{ }^{\circ} \mathrm{C}$ at take-off, have a key impact on the selection of materials, especially for turbine blades used in the hot part of the engine - nickel superalloys [3]. An example of a solution to increase the operating temperature is the use of cooling channels [4]. Due to limitations in the geometry of channels produced in the precision casting process, in recent years there has been a noticeable development of additive technologies that annihilate the existing limitations of manufacturing methods, allowing for increasing the efficiency of conformal cooling and other components of the geometry of the blades of engine elements used in aviation. Despite the indicated advantage in designing geometry, the number of available materials in the laser additive manufacturing process is limited to a narrow group of superalloys such as Inconel 625 [5], Inconel 718 [6] or Inconel 738LC [7], which do not have properties suitable for use on elements rotating in turbines. One of the reasons for the low availability of materials for additive manufacturing is the difficulty in welding nickel superalloys used for this type of elements due to the low thermal conductivity or high content of aluminum and titanium, which are responsible for the formation of the $\mathrm{Ni}_{3} \mathrm{Al}$ phase. Its nucleation generates additional stresses in the structure, which may lead to cracking of the material [8]. However, the Laser Powder Bed Fusion (LPBF) process has features that are considered beneficial in welding in the context of welding nickel superalloys. A highly focused beam of energy reduces the heat-affect zone and minimizes the amount of melted material per time unit, and thus the level of stresses arising during alloy crystallization [9]. Additionally, high cooling rates of up to $10^{5} \mathrm{~K} / \mathrm{s}$ result in the production of the material in a supersaturated state, which limits the formation of low-melting carbide phases during the process [10], the melting of which may cause cracking at the grain boundaries [11]. Using the DMLS method belonging to the LPBF technology, an attempt was made to additively manufacture samples of the Inconel 713C nickel superalloy used for blades, which is a constitutive alloy for new generation foundry nickel superalloys [12], and to study the effect of heat treatments on its microstructure and hardness. The investigated alloy was selected due to the very narrow range of high-temperature brittleness amounting to $40{ }^{\circ} \mathrm{C}$, which additionally reduces its susceptibility to crystallization cracking [13]. 


\section{Material and research methods}

LPW-713C-AABB powder (Carpenter Additive, Great Britain) with the chemical composition corresponding to the AMS5391H standard [14] (Table I) was used for the tests. The powder morphology was examined using the TM-1000 Scanning Electron Microscope (Hitachi, Japan) and the particle size distribution was determined using the Partica LA-950 Laser Diffraction Analyzer (Horiba, Japan).

Table I. Chemical composition of Inconel 713C superalloy regarding to AMS5391H

\begin{tabular}{ccccccccc}
\hline Element & $\mathbf{N i}$ & $\mathbf{C r}$ & $\mathbf{M o}$ & $\mathbf{A l}$ & $\mathbf{~ N b}$ & $\mathbf{T i}$ & $\mathbf{Z r}$ & $\mathbf{B}$ \\
\hline Weight percentage [\%] & 73 & 14 & 4.5 & 6 & 2.3 & 0.75 & 0.1 & 0.01 \\
\hline
\end{tabular}

The DMLS process was carried out using an EOS M100 device (EOS, Germany) using a laser power in the range of $10 \div 170 \mathrm{~W}$, for which the diameter of the focused laser spot is $40 \mu \mathrm{m}$. For all the processes carried out, heating of the working platform to a maximum temperature of $80^{\circ} \mathrm{C}$ was used, and the oxygen content in the chamber was controlled below 1000 ppm using argon with a purity of N5.0 as a shielding gas, in order to reduce the oxidation of the metal surface, which could affect its wettability, causing delamination between the produced layers [15].

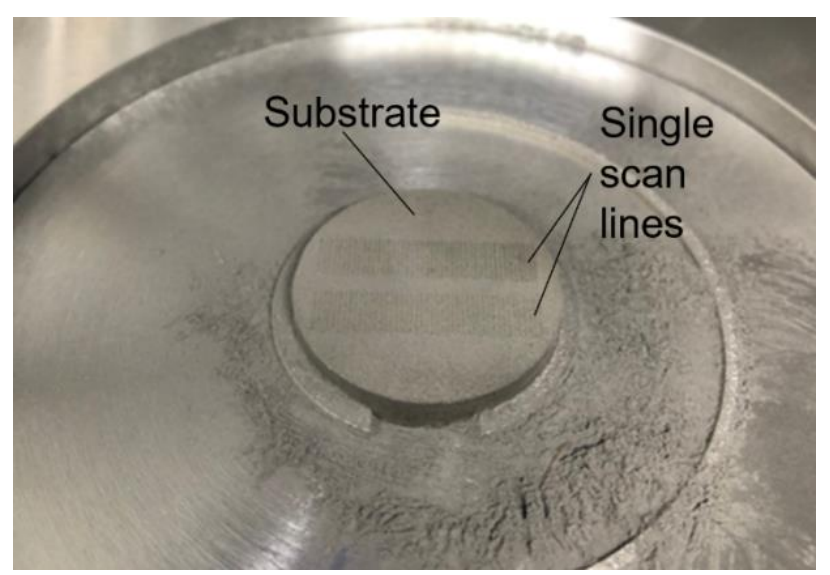

(a)

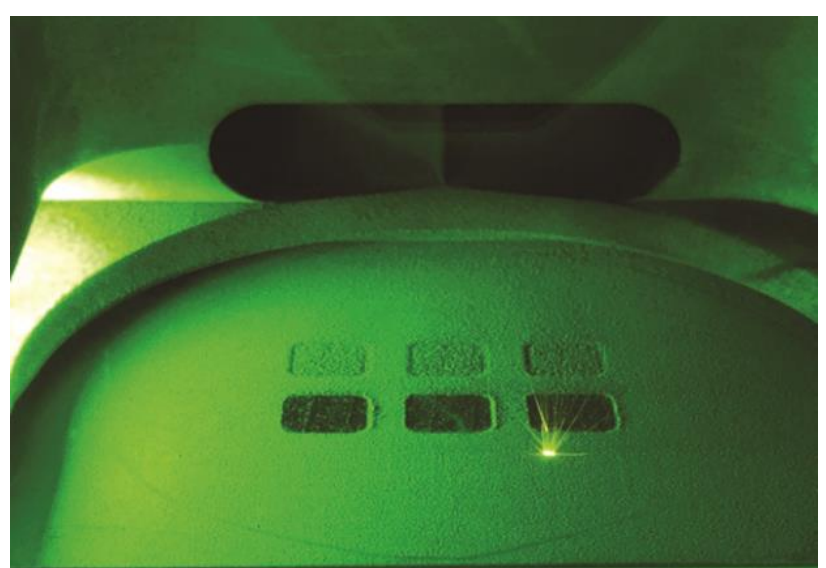

(b)

Fig. 1. a) Single scan lines on substrate from parent material; b) Additive manufacturing of three-dimensional samples

The optimization of technological parameters was started with the study of the stability of single scan lines $5 \mathrm{~mm}$ long as a function of linear energy density (Fig. 1a). In the next stage, samples in the form of a cube with a side of $10 \mathrm{~mm}$ were produced in order to optimize the spacing between laser remelts (Fig. 1b). A scanning strategy was used in which the scanning lines, in relation to the previous layer, are rotated by an angle of $67^{\circ}$ in order to reduce the emerging thermal stresses [16]. A single layer of material with a thickness of $20 \mu \mathrm{m}$ was remelted more than once in order to increase the energy supplied and heal any cracks [17]. Heat treatment was carried out for the selected set of laser power parameters, laser speed (linear energy density components), distances between scan lines and layer thickness.

The microstructure was examined using a Zeiss Axio Scope optical microscope (Carl Zeiss, Germany) and a TM-1000 in the $\mathrm{XZ}$ plane, where $\mathrm{X}$ is the direction of powder build-up and $\mathrm{Z}$ is the build direction on samples prepared according to a standard metallographic procedure.

The heat treatment was carried out in a Nabertherm NR 11/HR furnace (Nabertherm, Germany) in an air atmosphere. The applied variants of heat treatment are presented in Table II. For all states, the aging treatment was performed under the same conditions in order to investigate the effect of post-process annealing. The reference point was the standard two-stage heat treatment for Inconel 713C alloy, in which the samples are heated together with the furnace at a rate of $10^{\circ} \mathrm{C} / \mathrm{min}$ and cooled in air [18]. Due to the existence of the strain age cracking mechanism [19] the samples heated at $1240{ }^{\circ} \mathrm{C}$ were not heated with a furnace, but were placed directly at a given temperature in order to maximize the heating speed of the samples. The use of higher temperature compensates for the time needed to heat the furnace, which additionally increases the mobility of the grain boundaries [20]. The samples were cooled with a furnace to the temperature of $1176^{\circ} \mathrm{C}$, and then in the air in order to reduce the stresses arising during cooling, which may lead to cracking at the grain boundaries [21]. 
Table II. Tested samples and variants of heat treatments and their markings

\begin{tabular}{cccccc}
\hline $\begin{array}{c}\text { Manufacturing } \\
\text { method }\end{array}$ & Designation & $\begin{array}{c}\text { Annealing } \\
\text { temperature }\left[{ }^{\circ} \mathrm{C}\right]\end{array}$ & $\begin{array}{c}\text { Annealing } \\
\text { time }[\mathbf{h}]\end{array}$ & $\begin{array}{c}\text { Ageing } \\
\text { temperature }\left[{ }^{\circ} \mathrm{C}\right]\end{array}$ & $\begin{array}{c}\text { Ageing } \\
\text { time }[\mathbf{h}]\end{array}$ \\
\hline Casting & $\mathrm{O}$ & - & - & - & - \\
DMLS & 3D & - & - & 976 & 16 \\
DMLS & A3D & - & - & 976 & 16 \\
DMLS & A1176 & 1176 & 2 & 976 & 16 \\
DMLS & A1240 & 1240 & 2 & 976 & 16 \\
DMLS & B1240 & 1240 & 16 & 976 & 16 \\
\hline
\end{tabular}

The hardness tests were carried out using the HRC method using a Zwick/Roell ZHR 4150LK hardness tester (ZwickRoell, Germany) by performing at least 3 measurements to check the repeatability of the results.

\section{Powder examination}

Figure 2a shows a SEM photo showing the shape of the powder close to spherical. You can see "satellites", powder particles much smaller in size than the average particle size that have fused into the larger particles of the dominant fraction. This affects the powder flow properties and its bulk density, which is $4,03 \mathrm{~g} / \mathrm{cm}^{3}$ [22]. The particle size measurement shown in Figure $2 \mathrm{~b}$ showed that the mean particle size was $19 \mu \mathrm{m}$, and the values of the $\mathrm{d} 10$ and $\mathrm{d} 90$ parameters were $11.7 \mu \mathrm{m}$ and $27.4 \mu \mathrm{m}$, respectively.

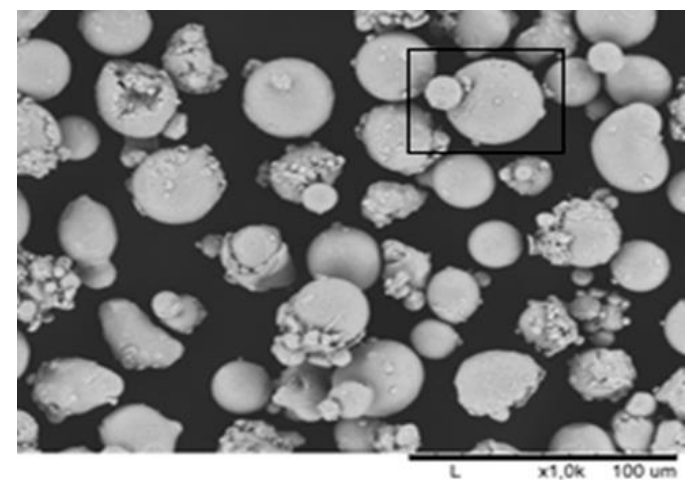

(a)

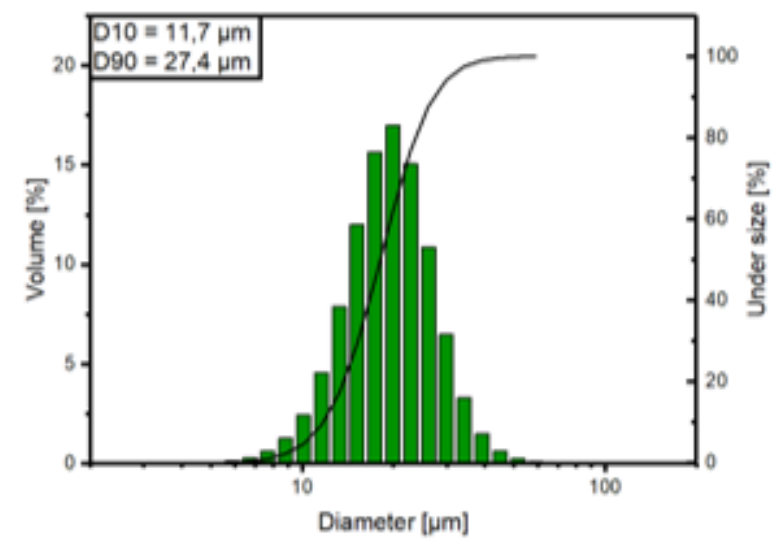

(b)

Fig. 2. a) Powder morphology; b) distribution of particles size

\section{Optimization of the DMLS process - linear energy density}

Figure 3a shows the sets of laser power and scanning speed parameters that were used in the next stage of additive manufacturing optimization. The selection was made from among 252 coupled pairs of technological parameters, which allowed to obtain a stable melting (Fig. 3b), without causing defects such as cracks and balling formation in the melt pool (Fig. 3c). In order to ensure adequate remelting between the layers of material, an additional assumption was to use the laser power above $80 \mathrm{~W}$. The range of linear energy density that meets the assumptions is $0.07 \div 0.15 \mathrm{~J} / \mathrm{mm}$.

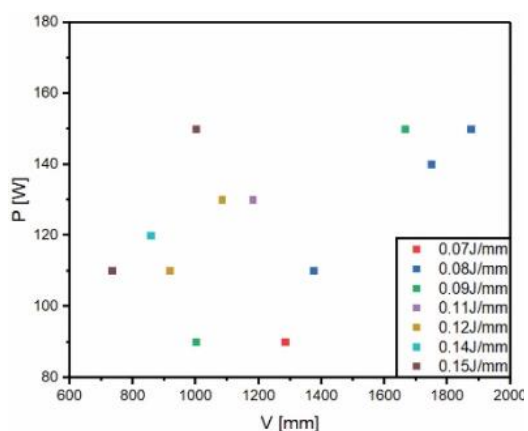

(a)

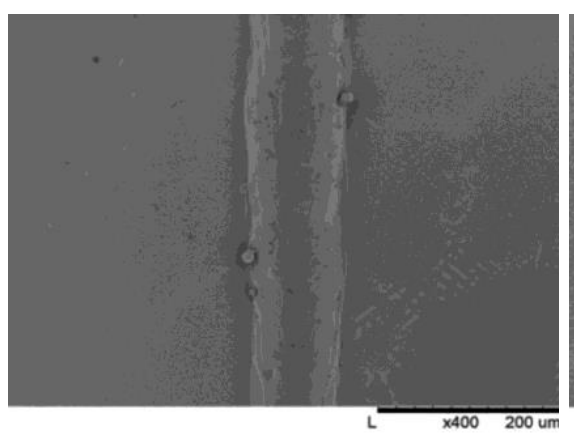

(b)

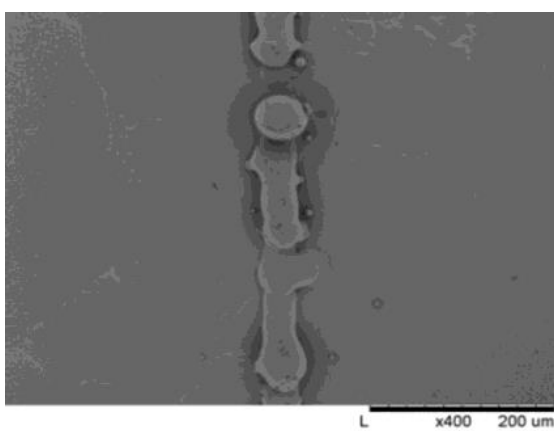

(c)

Fig. 3. a) Coupled technological parameters meeting the assumptions of stable melting; b) stable single scan line; c) unstable single scan line 


\section{Optimization of the DMLS process - distance between paths of the laser}

The next step was to optimize the distance between paths of the laser. Too large gaps $(>0.08 \mathrm{~mm})$ resulted in the lack of fusion of the material, leading to porosity, and even the presence of unmelted powder particles in the material (Fig. 4a, b). In the optimized DMLS production process, there were still single cracks and micropores (Fig. 4c, d).

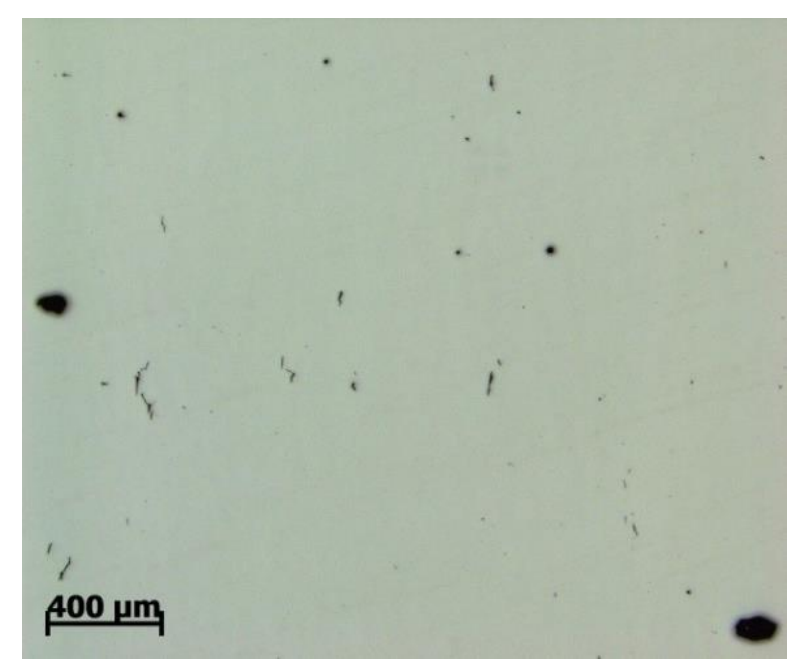

(a)

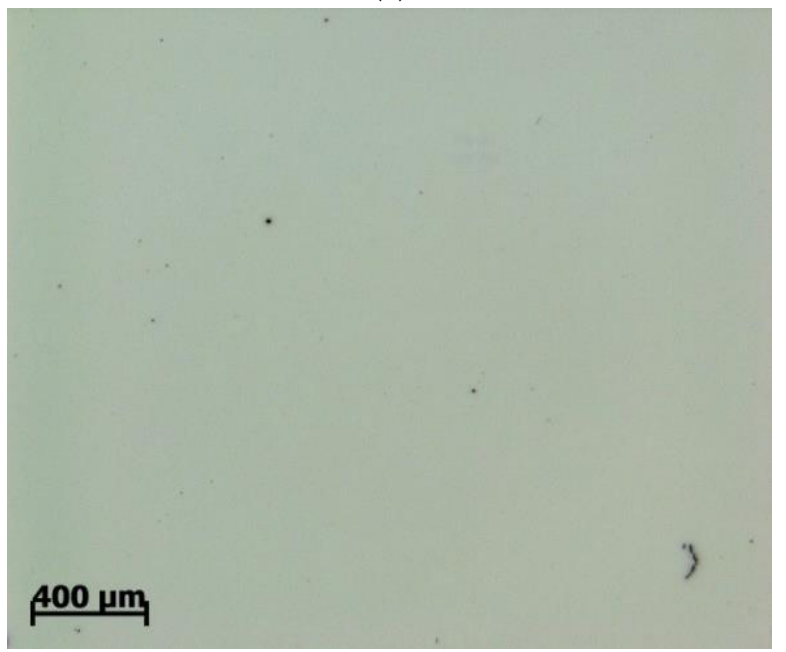

(c)

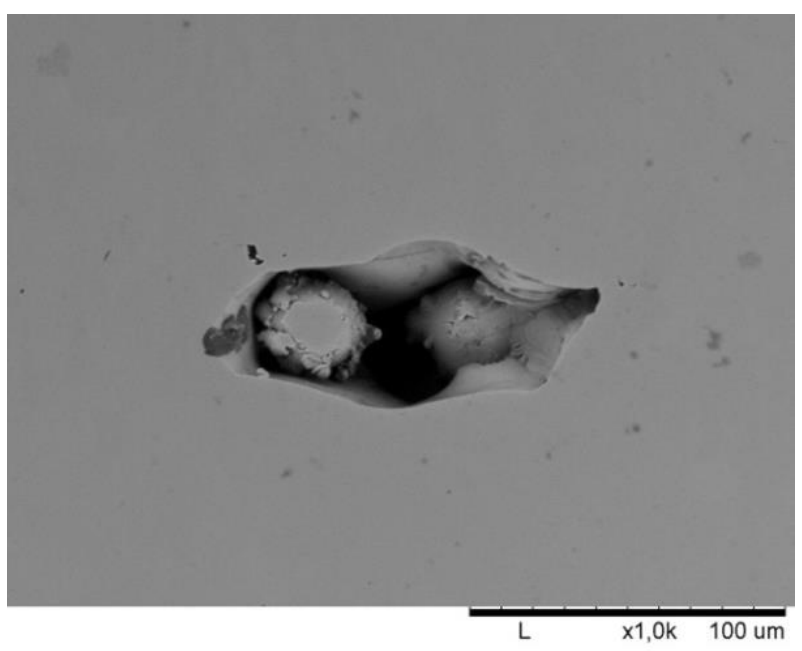

(b)

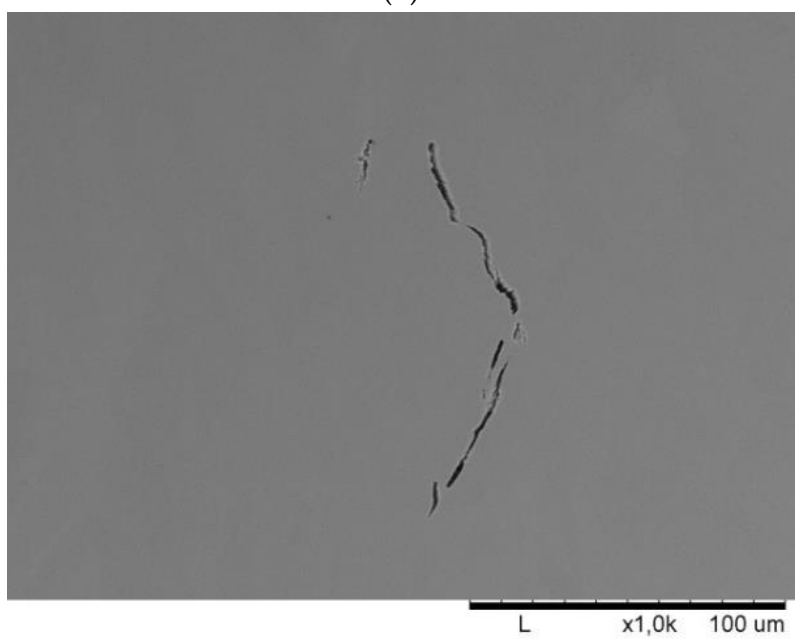

(d)

Fig. 4. a) Defective sample; b) Defect with unmelted powder; c) Optimized sample; d) Microcrack

\section{Light microscopy with the use of polarized light}

Observations in polarized light showed that the melt pools are characterized by the polarization of the light in such a way that the direction of crystallization in the direction of the weld axis is visible (Fig. 5a). Observations of the samples after heat treatment A1176 (fig. 5b) and A1240 (Fig. 5c) revealed that the same polarization effect occurs in their microstructure. Compared to sample B1240 (Fig. 5d), it allows to state that in these samples only partial recrystallization of the material took place, which influenced the morphology of the $\mathrm{Ni}_{3} \mathrm{Al}$ phase in the tested samples [23].

\section{Scanning electron microscopy}

The key phase for Inconel $713 \mathrm{C}$ superalloy is $\mathrm{Ni} 3 \mathrm{Al}$, which is already formed during casting and has a size of approx. $500 \mathrm{~nm}$ (Fig. 6a). Due to the slow cooling, the dendrites formed have a size of several millimeters [24]. The material after the DMLS process is characterized by the presence of very fine dendrites, which favors the homogenization of the material due to the directly proportional dependence of time on the square of the dendrite arm width [25]. The grain growth is not limited to the area of a single melt pool due to the melting of the previously formed grains in the previous layer, leading to epitaxial growth [26]. As a result of high cooling rates, the presence of the $\mathrm{Ni}_{3} \mathrm{Al}$ reinforcing phase is not found (Fig. 6b), therefore the first tested heat treatment is direct aging of the samples after the DMLS process. During aging, dendritic segregation 
disappeared. The resulting grains are columnar and grow along the direction of heat dissipation (Fig. 6c). The microstructures after heat treatment A1176 (fig. 6d) and A1240 (fig. 6e) are very similar, but due to the use of higher temperature, carbon diffusion has increased, which makes the boundaries in the material more visible due to the growth of carbides. Extending the annealing time had a positive effect on the cubic morphology of the $\mathrm{Ni}_{3} \mathrm{Al}$ phase (Fig. $6 \mathrm{f}$ ). The share of grain boundaries in the material has decreased, so the resulting carbide phases have the largest dimensions among the tested samples. Table III presents the dimensions of the $\mathrm{Ni}_{3} \mathrm{Al}$ phase and its morphology.

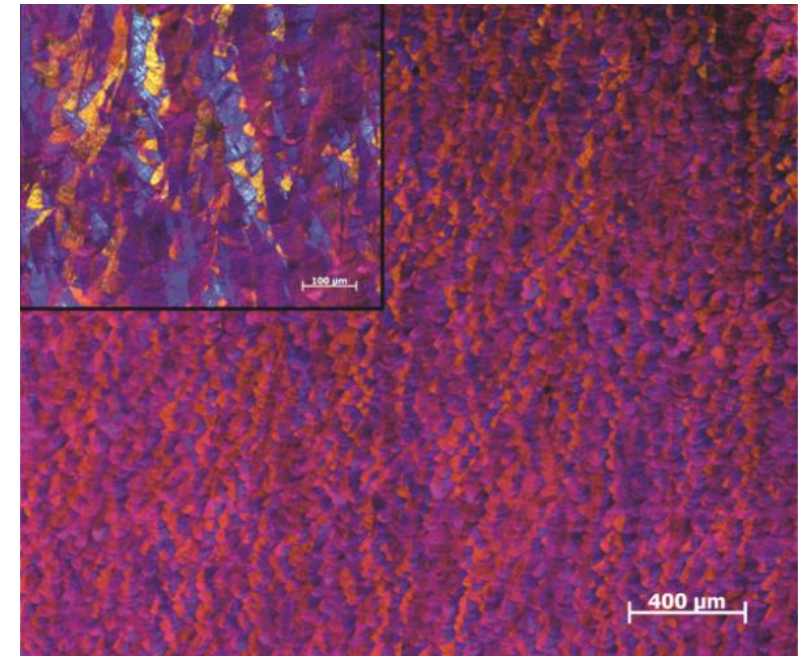

(a)

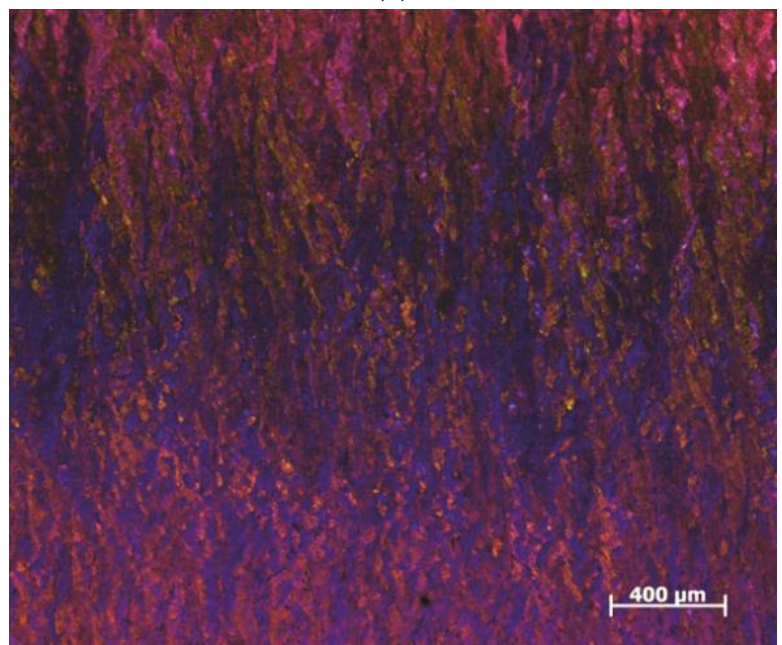

(c)

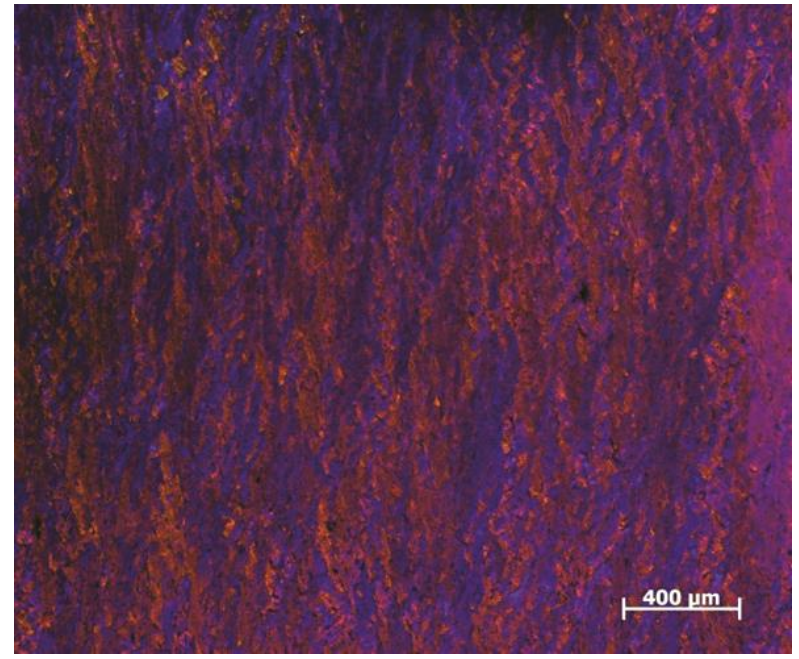

(b)

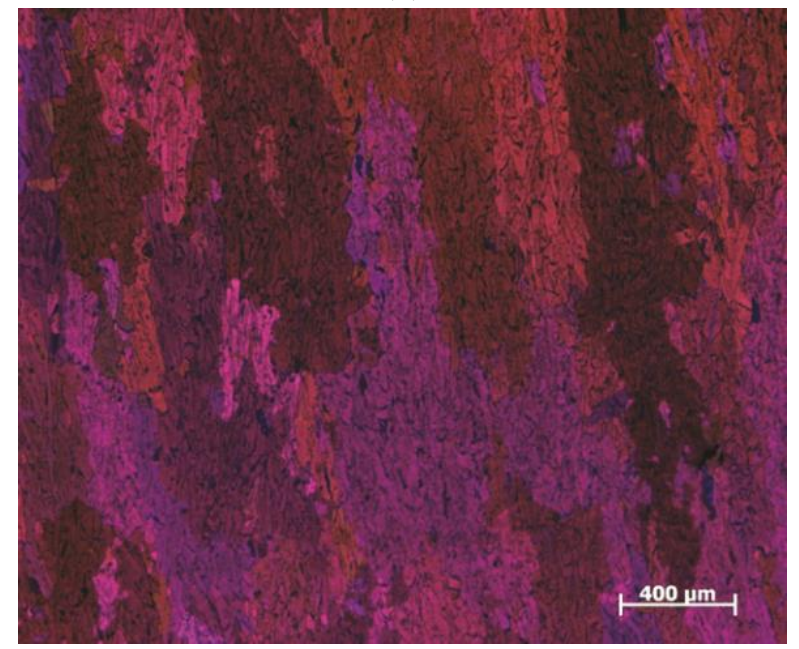

(d)

Fig. 5. Microstructure of samples in polarized light: a) 3D; b) A1176; c) A1240; d) B1240

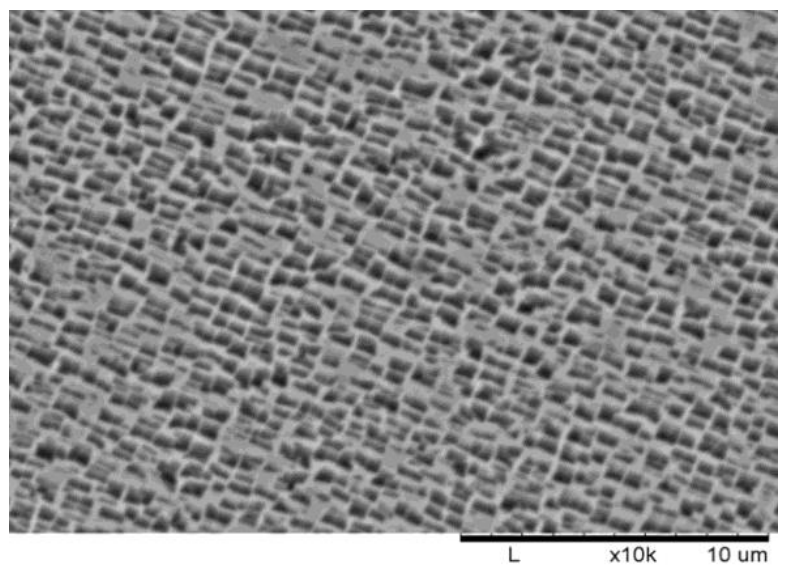

(a)

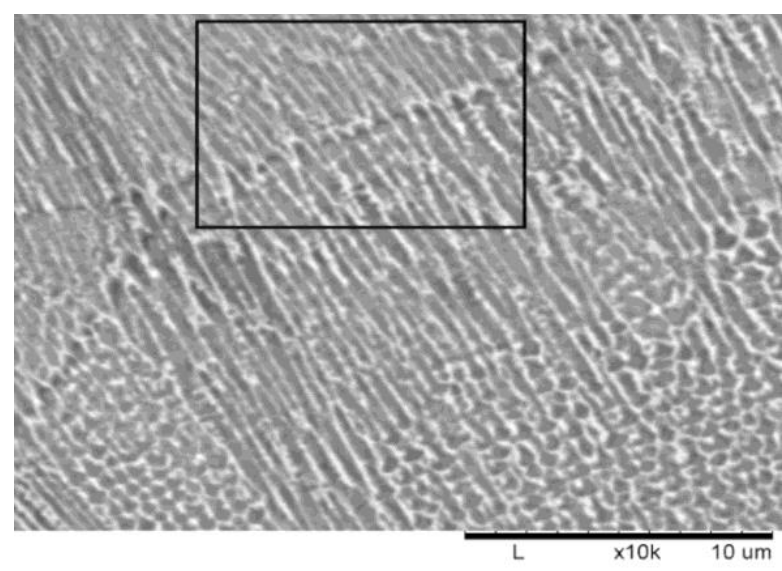

(b) 


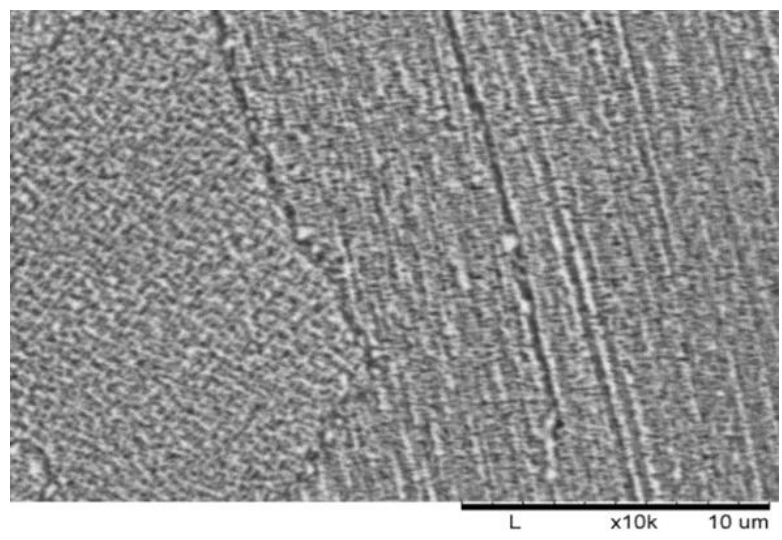

(c)

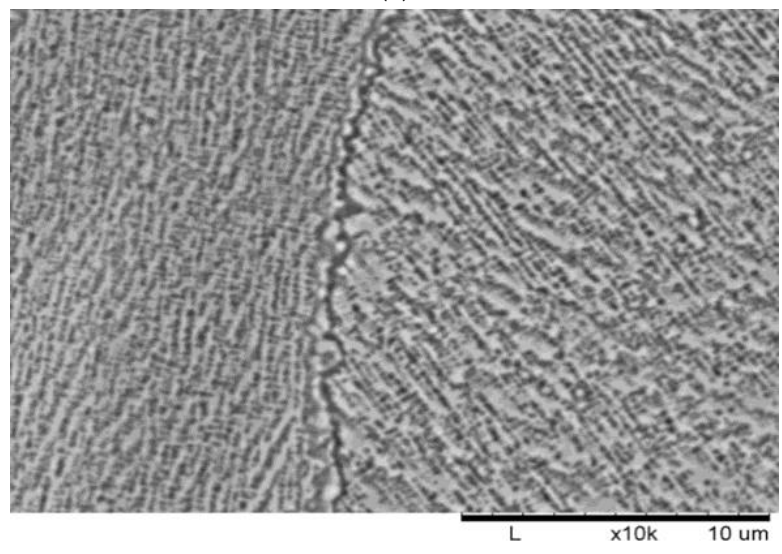

(e)

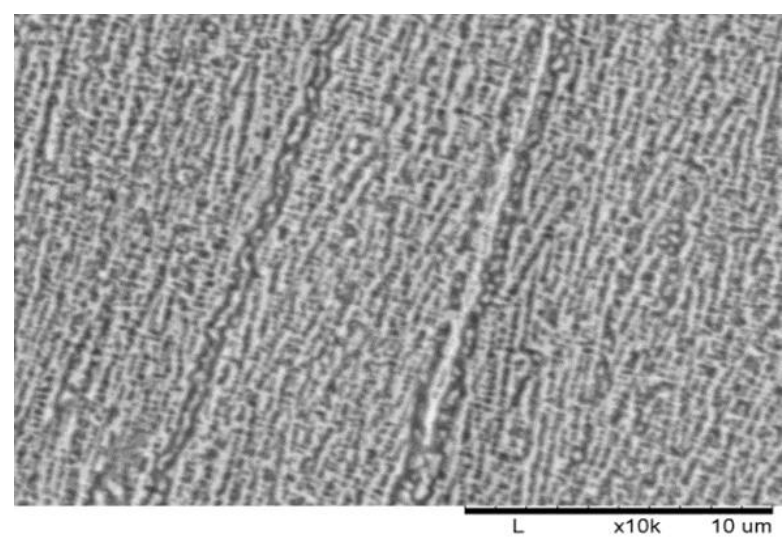

(d)

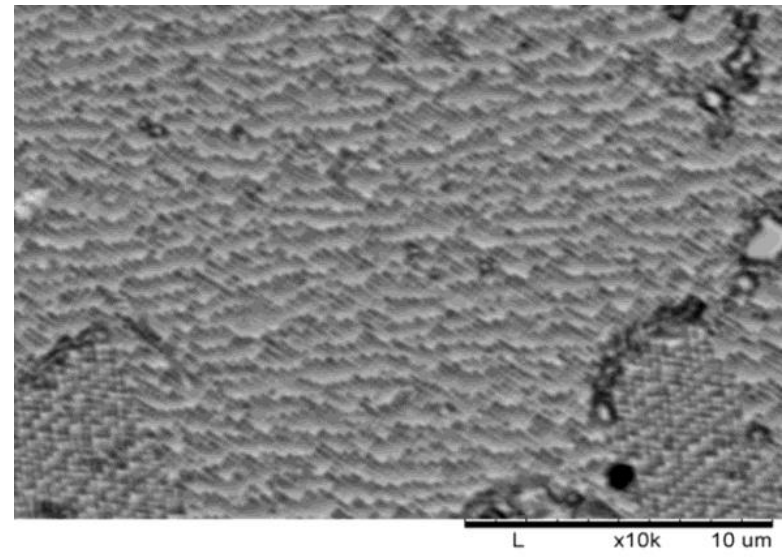

(f)

Fig. 6. Microstructure of samples: a) O; b) 3D; d) A1176; e) A1240; f) B1240

Table III. Size and morphology of the $\mathrm{Ni}_{3} \mathrm{Al}$ phase formed in different variants of heat treatment

\begin{tabular}{ccc}
\hline Sample & Phase size [nm] & Phase morphology \\
\hline O & 500 & "Split-cube" \\
3D & - & - \\
A3D & 175 & Near cuboidal \\
A1176 & 250 & Near cuboidal \\
A1240 & 250 & Near cuboidal \\
B1240 & 200 & Cubic \\
\hline
\end{tabular}

\section{HRC hardness measurements}

Inconel 713C nickel superalloy samples after DMLS process exceed the hardness of the alloy produced by casting. The highest hardness was demonstrated by the alloy subjected only to aging (A3D), reaching 46.3 HRC. The increase in hardness obtained after aging against the material after the DMLS process is visible. The material subjected to standard heat treatment, A1176, obtained a lower hardness than A1240, which shows that the higher temperature annealing the material after DMLS has a positive effect on its hardness. The last variant of the B1240 treatment obtained the lowest value among all DMLS samples, this may be due to a significant reduction in the share of grain boundaries, and thus the strengthening mechanism determined by the Halla-Petcha relationship [27] (Table IV).

Table. IV. The results of HRC hardness measurements

\begin{tabular}{ccccc}
\hline Sample & Measurement 1 & Measurement 2 & Measurement 3 & Average value \\
\hline O & 37 & 38 & 37 & 37 \\
3D & 42 & 42 & 43 & 42 \\
A3D & 46 & 47 & 46 & 46 \\
A1176 & 43 & 44 & 43 & 43 \\
A1240 & 44 & 44 & 44 & 44 \\
B1240 & 42 & 42 & 42 & 42 \\
\hline
\end{tabular}




\section{Conclusions}

On the basis of the conducted research, it is concluded:

- The previous melted layer in the DMLS process affects the method of crystallization of the next layer of material as a result of epitaxial growth.

- The NisAl phase formed in the tested variants of heat treatment after the DMLS process is smaller than in the as-cast material.

- Heat treatment after DMLS allows to obtain higher values of HRC hardness, significantly exceeding the hardness of the material in the as-cast state.

- Based on observation in polarized light, it is concluded that the standard heat treatment applied to Inconel $713 \mathrm{C}$ superalloy does not allow the material to fully recrystallize after the DMLS process, and consequently does not ensure microstructure stability. The use of the higher annealing temperature of $1240^{\circ} \mathrm{C}$ had a positive effect only on the hardness of the material. Longer annealing times are required.

Author Contributions: Conceptualization, J.C., R.S.; Methodology, J.C.; Software, J.C.; Validation, J.C., R.S., J.M.; Formal analysis, J.C.; Investigation, J.C.; Resources, J.C, R.S, J.M.; Data curation, J.C.; Writing - original draft preparation, J.C.; Writing - Review and editing, J.C., R.S., J.M.; Visualization, J.C.; Supervision, J.M.; Project administration, R.S.; Obtaining financing, J.M.

Funding: The research was financed as part of the statutory work Nr 504/04208/1080/44.000000.

Conflicts of Interest: The authors declare no conflict of interest.

\section{References}

[1] Masiol M., Harrison R.M., Aircraft engine exhaust emissions and other airport-related contributions to ambient air pollution: A review. Atmospheric Environment, 2014, Vol. 95, 409-55. https://doi.org/10.1016/j.atmosenv.2014.05.070

[2] Fulara S., Chmielewski M., Gieras M., Variable geometry in miniature gas turbine for improved performance and reduced environmental impact. Energies, 2020, Vol. 13(19). https://doi.org/10.3390/en13195230

[3] Nguyen T.H., Tri Nguyen P., Garnier F., Evaluation of the relationship between the aerothermodynamic process and operational parameters in the high-pressure turbine of an aircraft engine. Aerospace Science and Technology, 2019, Vol. 86, 93-105. https://doi.org/10.1016/j.ast.2019.01.011

[4] Lu Z.L., Cao J.W., Jing H., Liu T., Lu F., Wang D.X., et al., Review of main manufacturing processes of complex hollow turbine blades: This paper critically reviews conventional and advanced technologies used for manufacturing hollow turbine blades.Virtual and Physical Prototyping, 2013, Vol. 8(2), 87-95. https://doi.org/10.1080/17452759.2013.790600

[5] Tian Z., Zhang C., Wang D., Liu W., Fang X., Wellmann D., et al., A review on laser powder bed fusion of inconel 625 nickel-based alloy. Applied Sciences, 2020, Vol. 10(1). https://doi.org/10.3390/app10010081

[6] Yang H., Yang J., Huang W., Jing G., Wang Z., Zeng X., Controllable in-situ aging during selective laser melting: Stepwise precipitation of multiple strengthening phases in Inconel 718 alloy. Journal of Materials Science $\mathcal{E}$ Technology, 2019, Vol. 35. https://doi.org/10.1016/j.jmst.2019.05.024

[7] Perevoshchikova N., Rigaud J., Sha Y., Heilmaier M., Finnin B., Labelle E., et al., Optimisation of selective laser melting parameters for the Ni-based superalloy IN-738 LC using Doehlert's design. Rapid Prototyping Journal, 2017, Vol. 23(5), 881-92. https://doi.org/10.1108/RPJ-04-2016-0063

[8] Ojo O.A., Richards N.L., Chaturvedi M.C., Contribution of constitutional liquation of gamma prime precipitate to weld HAZ cracking of cast Inconel 738 superalloy. Scripta Materialia, 2004, Vol. 50(5), 641-6. https://doi.org/10.1016/j.scriptamat.2003.11.025

[9] Chamanfar A., Jahazi M., Bonakdar A., Morin E., Firoozrai A., Cracking in fusion zone and heat affected zone of electron beam welded Inconel-713LC gas turbine blades. Materials Science and Engineering A, 2015, Vol. 642, $230-40$. https://doi.org/10.1016/j.msea.2015.06.087

[10] Chen Z., Chen S., Wei Z., Zhang L., Wei P., Lu B., et al., Anisotropy of nickel-based superalloy K418 fabricated by selective laser melting. Progress in Natural Science: Materials International, 2018, Vol. 28. https://doi.org/10.1016/j.pnsc.2018.07.001

[11] Adamiec J., Łyczkowska K., Remelting of inconel 713C alloy by laser and plasma arc. Welding Technology Review, 2017, Vol. 89(5). https://doi.org/10.26628/ps.v89i5.757

[12] Long H., Mao S., Liu Y., Zhang Z., Han X., Microstructural and compositional design of Ni-based single crystalline superalloys - A review. Journal of Alloys and Compounds, 2018, Vol. 743, $203-20$. https://doi.org/10.1016/j.jallcom.2018.01.224

[13] Łyczkowska K., Adamiec J., Jachym R., Kwieciński K., Properties of the Inconel 713 Alloy Within the High Temperature Brittleness Range. Arch. of Foundry Engineering, 2017, Vol. 17. https://doi.org/10.1515/afe-2017-0138

[14] AMS5391H: Nickel Alloy, Corrosion and Heat Resistant, Investment Castings, 73Ni - 13Cr - 4.5Mo - 2.3Cb (Nb) 0.75Ti - 6.0Al - 0.010B - 0.10Zr Vacuum Cast, As-Cast - SAE International. 
[15] Ye D., Hsi Fuh J.Y., Zhang Y., Hong G.S., Zhu K., In situ monitoring of selective laser melting using plume and spatter signatures by deep belief networks. ISA Transactions, 2018, Vol. 81(May 2019), 96-104. https://doi.org/10.1016/j.isatra.2018.07.021

[16] Cheng B., Shrestha S., Chou K., Stress and deformation evaluations of scanning strategy effect in selective laser melting. Additive Manufacturing, 2016, Vol. 12. https://doi.org/10.1016/j.addma.2016.05.007

[17] Xiong Z., Zhang P., Tan C., Dong D., Ma W., Yu K., Selective Laser Melting and Remelting of Pure Tungsten. Advanced Engineering Materials, 2020, Vol. 22(3), 1901352. https://doi.org/10.1002/adem.201901352

[18] Galizoni B.B., Couto A.A., Reis D.A.P., Heat treatments effects on nickel-based superalloy inconel 713C. Metals, 2019, Vol. 9(1). https://doi.org/10.3390/met9010047

[19] Lachowicz M., Dudziński W., Haimann K., Podrez-Radziszewska M., Microstructure transformations and cracking in the matrix of $\gamma-\gamma^{\prime}$ superalloy Inconel 713C melted with electron beam. Materials Science and Engineering A, 2008, Vol. 479. https://doi.org/10.1016/j.msea.2007.06.064

[20] Safarloo S., Loghman F., Azadi M., Azadi M., Optimal Design Experiment of Ageing Time and Temperature in Inconel-713C Superalloy Based on Hardness Objective. Trans. of the Indian Institute of Metals, 2018, Vol. 71(7).

[21] Jonšta P., Jonšta Z., Sojka J., Čížek L., Hernas A., Structural characteristics of nickel super alloy INCONEL 713LC after heat treatment. Journal of Achiev. in Materials and Manufacturing Engineering, 2007, Vol. 21(2), $29-32$.

[22] Chu F., Zhang K., Shen H., Liu M., Huang W., Zhang X., et al., Influence of satellite and agglomeration of powder on the processability of AlSi10Mg powder in Laser Powder Bed Fusion. Journal of Materials Research and Technology, 2021, Vol. 11, 2059-73. https://doi.org/10.1016/j.jmrt.2021.02.015

[23] Zhang B., Tao C., Lu X., Liu C., Hu C., Bai M., Recrystallization of single crystal nickel-based superalloy. Journal of Iron and Steel Research International, 2009, Vol. 16(6). https://doi.org/10.1016/S1006-706X(10)60031-3

[24] Nawrocki J., Gancarczyk K., Manaj W., Albrecht R., Cygan R., Krupa K., The Effect of Superalloy Structure on Ultrasonic Wave Parameters. Fatigue of Aircraft Structures, 2015, Vol. 1. https://doi.org10.1515/fas-2015-0010

[25] Körner C., Ramsperger M., Meid C., Bürger D., Wollgramm P., Bartsch M., et al., Microstructure and Mechanical Properties of CMSX-4 Single Crystals Prepared by Additive Manufacturing. Metallurgical and Materials Transactions A: Physical Metallurgy and Materials Science, 2018, Vol. 49(9), 3781-92. https://doi.org/10.1007/s11661-018-4762-5

[26] Aboulkhair N.T., Simonelli M., Parry L., Ashcroft I., Tuck C., Hague R., 3D printing of Aluminium alloys: Additive Manufacturing of Aluminium alloys using selective laser melting. Progress in Materials Science, 2019, Vol. 106. https://doi.org/10.1016/j.pmatsci.2019.100578

[27] Liu W.H., Wu Y., He J.Y., Nieh T.G., Lu Z.P., Grain growth and the Hall-Petch relationship in a high-entropy FeCrNiCoMn alloy. Scripta Materialia, 2013, Vol. 68(7), 526-9. https://doi.org/10.1016/j.scriptamat.2012.12.002

(C) 2021 by the authors. Submitted for possible open access publication under the terms and conditions of the Creative Commons Attribution (CC BY) license (http://creativecommons.org/licenses/by/4.0/). 